\title{
Revisiting the 1992 severe drought episode in South Africa: the role of El Niño in the anomalies of atmospheric circulation types in Africa south of the equator
}

\author{
Chibuike Chiedozie Ibebuchi ${ }^{1}$ D
}

Received: 6 April 2021 / Accepted: 21 July 2021 / Published online: 31 August 2021

(c) The Author(s) 2021, corrected publication 2021

\begin{abstract}
During strong El Niño events, below-average rainfall is expected in large parts of southern Africa. The 1992 El Niño season was associated with one of the worst drought episodes in large parts of South Africa. Using reanalysis data set from NCEPNCAR, this study examined circulation types (CTs) in Africa south of the equator that are statistically related to the El Niño signal in the southwest Indian Ocean and the implication of this relationship during the 1992 drought episode in South Africa. A statistically significant correlation was found between the above-average Nino 3.4 index and a CT that features widespread cyclonic activity in the tropical southwest Indian Ocean, coupled with a weaker state of the south Indian Ocean high-pressure. During the analysis period, it was found that the El Niño signal enhanced the amplitude of the aforementioned CT. The impacts of the El Niño signal on CTs in southern Africa, which could have contributed to the 1992 severe drought episode in South Africa, were reflected in (i) robust decrease in the frequency of occurrence of the austral summer climatology pattern of atmospheric circulation that favors southeasterly moisture fluxes, advected by the South Indian Ocean high-pressure; (ii) modulation of easterly moisture fluxes, advected by the South Atlantic Ocean high-pressure, ridging south of South Africa; (iii) and enhancement of the amplitude of CTs that both enhances subsidence over South Africa, and associated with the dominance of westerlies across the Agulhas current. Under the ssp585 scenario, the analyzed climate models suggested that the impact of radiative heating on the CT significantly related to El Niño might result in an anomalous increase in surface pressure at the eastern parts of South Africa.
\end{abstract}

Keywords South Africa $\cdot$ Circulation type $\cdot 1992$ El Niño season $\cdot$ Moisture fluxes $\cdot$ Drought

\section{Introduction}

South Africa, situated at the descending branch of the Hadley circulation, is prone to drought (Baudoin et al. 2017). However, the 1992 drought episode in South Africa is characterized as one of the most severe in history (Glantz et al. 1997; Mason and Tyson 2000). Its occurrence during the 1991/1992 growing season significantly impacted agricultural activities and food security, resulting in the demand for increased efficiency in the management of drought events in South Africa (Bruwer 1993). Moreover, under greenhouse gas-induced climate change,

Chibuike Chiedozie Ibebuchi

chibuike.ibebuchi@uni-wuerzburg.de

1 Institute of Geography and Geology, University of Würzburg, Am Hubland, 97074 Würzburg, Germany dry spell is expected to increase in South Africa (IPCC 2013). Hence, using the 1992 severe drought episode as a reference, which equally is recorded as a strong El Niño year (Glantz et al. 1997), this study investigates how the interrelation between the El Niño Southern Oscillation (ENSO) and circulation types (CTs) in Africa south of the equator might have contributed to the drought episode and how the analysis might be beneficial for enhanced understanding of the synoptic-scale causes of drought events in South Africa.

Among the different teleconnection signals in the south Indian Ocean, ENSO plays a significant role in the interannual variability of rainfall in South Africa (Reason et al. 2005). ENSO has two phases-El Niño and La Niña-that can influence atmospheric circulations and patterns of precipitation in southern Africa (Jury et al. 1994; Reason et al. 2000). Strong El Niño years are usually accompanied by below-average rainfall in most regions in southern Africa 
and vice versa for La Niña years. The origin of ENSO is related to tropical Pacific sea surface temperature (SST) anomalies, and the energy released by the resulting moderations in convection in the tropical Indian Ocean and the Pacific Ocean induces Rossby waves over southern Africa (Hoell et al. 2015). According to Reason and Jagadheesha (2005), the regional fluxes of moisture in southern Africa can be modulated by the excited Rossby waves. Manatsa et al. (2015) noted that the relationship between southern Africa rainfall and ENSO is strongest in December-March (DJFM). The South Indian Ocean Convergence Zone (SICZ) is the major synoptic feature that modulates the austral summer (DJF) rainfall variability in southern Africa (Cook 2000; Ninomiya 2008). Cook (2000) reported that during strong El Niño events, the SICZ undergoes a northeastward shift. Thus, ENSO might be able to constrain the major regional rain-bearing atmospheric circulation features in southern Africa that result in the formation of the SICZ - such as the South Indian Ocean high-pressure and the Angola low. Hoell et al. (2015) reported that in southern Africa, vertical motions can be modified by ENSO events. Also, a weakening of the South Indian highpressure and the Angola low might be expected during strong El Niño events (Cook 2000; Reason and Jagadheesha 2005).

It is also necessary to note that given the remote influence of ENSO, the predictability of drought in South Africa is not always well correlated with El Niño (Reason and Jagadheesha 2005). For example, during the 1997/1998 El Niño event, rainfall reduction was projected in southern Africa but this failed to materialize (Lyon and Manson 2007). However, SST anomalies in the southwest Indian Ocean, Benguela current, the Greater Agulhas region, and variations in synoptic systems such as the South Indian Ocean high-pressure and the South Atlantic Ocean high-pressure influence moisture uptake in the adjacent oceans, moisture transport to South Africa, and so rainfall formation in the region (Walker 1990; Reason and Mulenga 1999; Vigaud et al. 2009; Driver 2014).

Several studies have used the Self-Organizing Maps (SOMs) to identify synoptic circulation over southern Africa (e.g., Lennard and Hegerl 2015; Engelbrecht et al. 2015, Engelbrecht and Landman 2016, Wolski et al. 2018; Odoulami et al. 2020). The capability of the SOM to generate non-linear solutions and its tendency to treat the data set as a continuum make it a better choice for circulation typing compared to hard clustering algorithms (e.g., K-means) that allow the classified variable to be assigned only to one class. However, given the continuous and fuzzy nature of atmospheric circulation patterns, a classification scheme that allows overlapping of the classified variable can result in relatively better classifications (Gong and Richman 1995; Xu and Tian 2015). The rotated principal component analysis technique fits such classification criteria since it is fuzzy by the nature of the PCA loadings. When CTs are defined using obliquely rotated PCA applied to a climate variable represented in T-mode (i.e., variable is time series and observations are grid point), the classified CTs can exhibit physically interpretable dipoles (Compagnucci and Richman 2008) related to the probability of specific weather events in the study region (Richman 1981). The major difference between the SOM and obliquely rotated T-mode PCA is that SOM classification is based on model (see Xu and Tian (2015) and Hewitson and Crane (2002) for detailed explanation), while the rotated PCA technique finds vector positions that maximize hyperplane counts and simultaneously find subsets of highly related variables (Richman 1981, 1986; Richman and Gong 1999).

In this study, CTs are defined using obliquely rotated T-mode PCA. Additionally, it is investigated if there is a modulation of the ENSO signal over the occurrence of the CTs. The physical interpretability of CTs that their amplitude or frequency are related to or influenced by ENSO will be examined by investigating if they reflect large-scale patterns of atmospheric circulation known a priori from existing works of literature that might be expected during ENSO events. During the 1992 El Niño season, the physical and statistical nature of the relationship between the selected synoptic situations and ENSO are investigated to understand how El Niño might constrain rain-bearing CTs in South Africa during the austral wet seasons in southern Africa. Thus, the strengths of this study are on the improved understanding of the mechanisms through which El Niño causes drought in South Africa in the light of anomalies in CTs in addition to highlighting how the statistical concept of circulation typing, achieved with obliquely rotated PCA, can be extended to the predictability of regional rainfall in southern Africa. The latter is of importance given the increased vulnerability of the hydroclimate of South Africa, and the need for simple approaches that can be applied by local weather agencies and water decision-makers in rainfall prediction in the study region.

\section{Data and methodology}

Sea level pressure (SLP); precipitation; specific humidity; and wind vectors at $850 \mathrm{hPa}$ data sets are obtained from NCEP-NCAR reanalysis (Kalnay et al. 1996). The data sets are obtained at horizontal and temporal resolutions of $2.5^{\circ}$ longitude and latitude, and daily from 1979 to 2020 , respectively. The precipitation data set 
is obtained at a Gaussian grid type and interpolated to $0.75^{\circ}$ longitude and latitude using First order conservative remapping (Jones 1999). Precipitation data set obtained from the Climate Prediction Center (CPC) (Xie et al. 2007) at a horizontal resolution of $0.5^{\circ}$ longitude and latitude and daily temporal resolution from 1981 to 2010 is used to validate the NCEP precipitation data set in South Africa.

The spatial extent for the circulation typing is $5.25^{\circ}$ $\mathrm{E}-55.25^{\circ} \mathrm{E}$ and $0^{\circ}-50.25^{\circ} \mathrm{S}$. The adjacent oceans are included to capture moisture advection processes. The classification steps with obliquely rotated T-mode PCA are the same as documented in Ibebuchi (2021a, b). Here it is applied to the daily z-score standardized SLP data set for the 1979-2020 period. The representation of the SLP data set in T-mode structure is based on the finding of Richman $(1981,1986)$ that classification of a field that explains atmospheric circulation and represented in the T-mode structure results in a simplified time-series isolating subgroups of observations with a coherent spatial pattern.

In the classification process, a correlation matrix is used to relate the time series. Singular value decomposition is used in factorizing the matrix to obtain the PC scores, eigenvalues, and eigenvectors. The eigenvectors are multiplied with the square root of their corresponding eigenvalues that make them longer than a unit length, referred to as loadings (Richman and Lamb 1985). The number of components to retain is first based on the philosophy of North et al. (1982) which implies retaining components with separated eigenvalues. However, since the subsequent steps require rotation of the retained components, the recommendation of North et al. (1982) might not be so useful; however, it was used as a first guess. Preisendorfer et al. (1981) explained that even components with low eigenvalues might still uncover vital climatic patterns; thus, the ultimate decision of the number of components to retain is based on ensuring that the further added components have not been delineated by previous vectors (Richman 1981).

The retained components are rotated obliquely using Promax at a power of 2 (Richman 1986). The oblique rotation of the PCs relaxes the orthogonality constraint and maximizes the number of near-zero loadings so that each component clusters a unique number of days (Richman 1981, 1986). The absolute value of the loadings designates an important signal and threshold values within the range of $0.2-0.35$ can be used to separate noise (i.e., loadings within the zero interval) from signal, depending on the effective sample size (Richman and Gong 1999). Given the large sample size, \pm 0.2 is used in this paper to cluster positive and negative loadings above the threshold for a given retained component. Thus, each retained component yields two clusters and the mean SLP of the days clustered under each class is the CT. This step increases the weather coherency and coherency in the time occurrence of the days clustered under each class. According to Gong and Richman (1995), another advantage that using rotated PCA offers despite the binarization with the $(0.2)$ threshold is that it is inherently fuzzy-i.e., in this case, a day can have its loading above the 0.2 threshold in more than one retained component-thus, overlapping of the classified variables is possible. Given that atmospheric circulation is a continuum, this feature is quite desirable. Another implication of the continuum nature of atmospheric circulation patterns is that though some CT(s) might tend to exhibit some seasonality, CTs are not confined to occur at any specific season; thus, to avoid information loss on the time-frequency distribution of the CTs, the complete seasons in a year are used for the classification. However, the annual cycle of the selected CTs significantly modulated by ENSO is further analyzed to uncover their probability to be dominant at specific season(s).

Previous classifications of CTs in Africa south of the equator (Ibebuchi 2021a, b) show that for a given retained component, the dipoles (i.e., clusters of positive and negative loadings above the 0.2 threshold) can be related to the inverse of synoptic situations under different opposite seasons. For example, a synoptic situation associated with continental heating (upward vertical motion) dominates in austral summer (DJF) while its inverse exhibits subsidence and dominates in austral winter (JJA). This is also a further added value in using the complete seasons for the classification. Thus, the loadings (which designate the amplitude of the CTs) under each retained component, comprising of positive and negative dipoles, are related to the standardized Nino 3.4 index using correlation analysis. Nino 3.4 index is obtained from https://psl.noaa.gov/gcos_wgsp/Times eries/Nino34/, and the correlation is done for the 1979 to 2020 period (excluding the years before the satellite era). A statistically significant correlation, at lag 0 , based on the Kendall's-Tau-b test at a 95\% confidence level (i.e., $p$ value $<0.05$ ), implies that ENSO is related to the component in question. Positive correlation coefficient $(R)$ implies that above-average Nino 3.4 index (El Niño) is related to the positive (dipole) phase of the component and vice versa for a negative correlation coefficient. Also, the correlation analysis is done between the Nino 3.4 index and the annual frequency of occurrence of the CTs. To investigate if ENSO influences the amplitude of the CTs, lagged correlation of up to 3 months between ENSO and the loadings of the CTs during the DJFM 
season was done. For example, a 1-month lagged correlation implies correlating the seasonal NDJF mean of the Nino 3.4 index with the DJFM loadings of a given retained component for the 1979-2020 period.

For the 1979-2020 period, strong El Niño (La Niña) events for the DJF season are subjectively defined as when the index is $>0.7(<-0.7) . \pm 0.7$ is used since generally, ESNO events ranked with it persisted into the JFM season, and DJFM is the period when the relationship between ENSO and southern African precipitation is the strongest. Years when the DJF index is within \pm 0.3 were chosen as ENSO neutral years. Anomalies in the annual frequency of occurrence and persistence of the CTs modulated by ENSO were calculated in these years as the difference between their longterm mean and their mean observation during the selected strong ENSO and neutral ENSO years. The aim is to investigate if the ENSO signal impacts the aforementioned features of the CTs. Also, seasonal rainfall anomalies associated with the selected wet CTs modulated by ENSO are investigated for the 1979-2020 period, with more focus on the 1992 wet season.

Finally, changes in the pressure field of the CT that is statistically related to El Niño were investigated under the ssp585 scenario (2065-2100) relative to the historical experiment (1979-2014) using the two climate models pre-selected in Ibebuchi (2021a). The GCMs are MPI-ESM-LR and EC-EARTH -CC. Both GCMs simulated well, the mean shape of the CT related to El Niño. Statistical significance of the anomalies is done using the permutation test at a $95 \%$ confidence level.

\section{Results}

\subsection{Climatology of precipitation in South Africa}

Figure 1 shows the seasonal climatology of precipitation in South Africa from the CPC and NCEP-NCAR data sets. Austral summer (DJF) is the wettest season and austral winter (JJA) is the driest season. During austral winter, the southwestern region of the Western Cape relatively receives rainfall by the activities of cold fronts. Southeastern coastal regions receive rainfall throughout the year. Generally, on the spatial scale, the northwestern regions are relatively arid due to proximity to the cold Benguela current while the northeastern regions are wettest due to proximity to the warm Agulhas current. From Fig. 2, December to March is relatively the wettest months. NCEP-NCAR overestimates rainfall during these months and this is evident in Fig. 1 at parts of the northeastern regions. In the austral winter months, NCEP-NCAR underestimates rainfall at southwestern regions of the Western Cape but overestimates rainfall at parts of the northeastern regions relative to the CPC data set. Generally, from Fig. 1 and Fig. 2, the annual cycle and spatial variability of precipitation from both data sets are

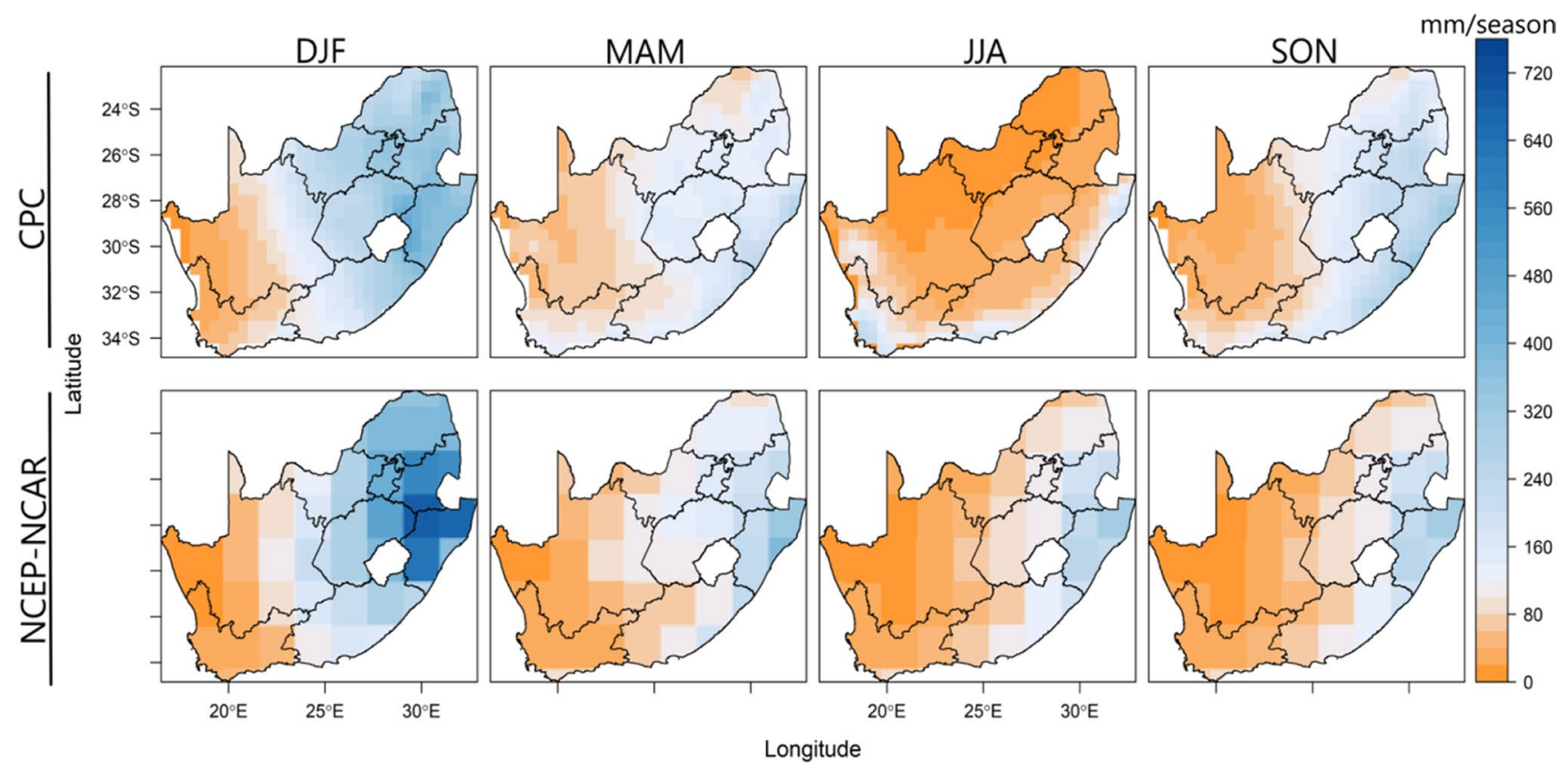

Fig. 1 Seasonal rainfall climatology in South Africa for the 1981-2010 period from the CPC and NCEP-NCAR data sets 


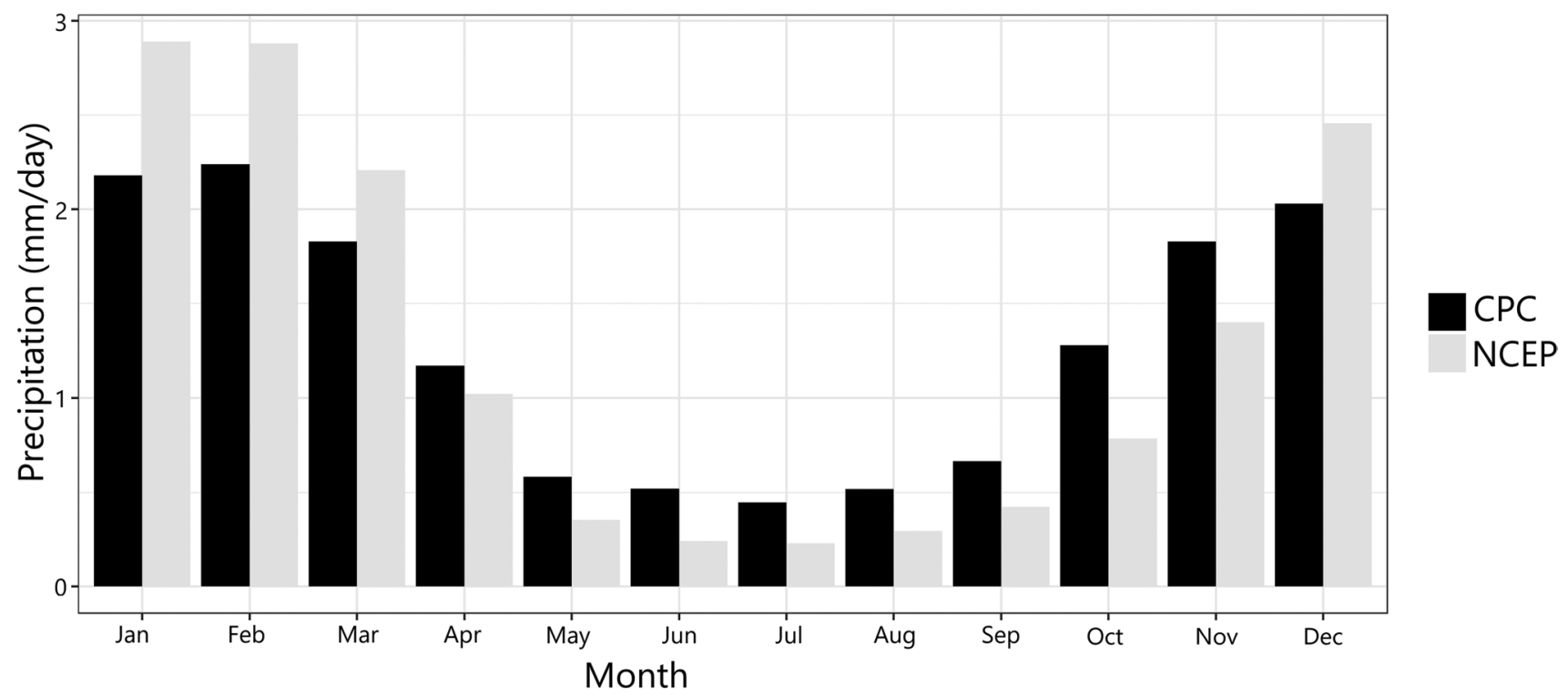

Fig. 2 Annual cycle of rainfall averaged over South Africa for the 1981-2010 period, from the CPC and NCEP-NCAR data sets

quite close (seasonal spatial correlation coefficient $>0.9$ ). The difference between the data sets is mostly in the magnitude of precipitation. The mean absolute error of precipitation averaged over South Africa between the two data sets for the analysis period is $0.89 \mathrm{~mm} / \mathrm{day}$. The variability of precipitation measured by the standard deviation is slightly higher in NCEP-NCAR (i.e., a bias of $+0.01 \mathrm{~mm} /$ day). The correlation coefficient of the daily values between the data


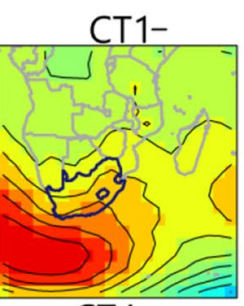

CT4-



CT7-

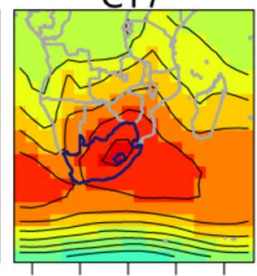

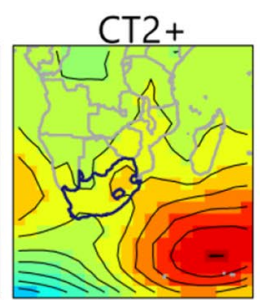

CT5+

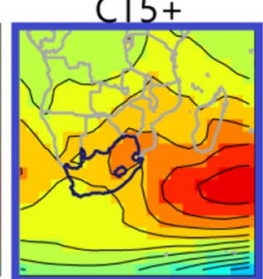

CT8+

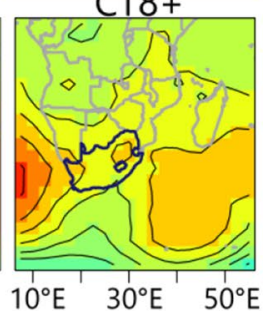

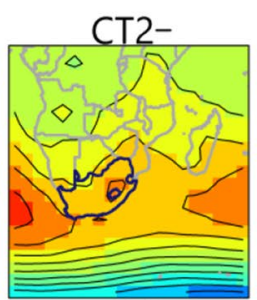

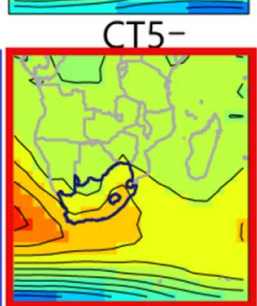

CT8-



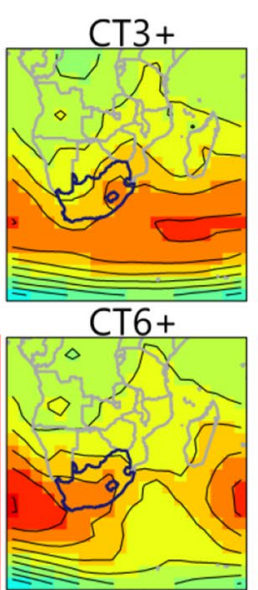

CT9+

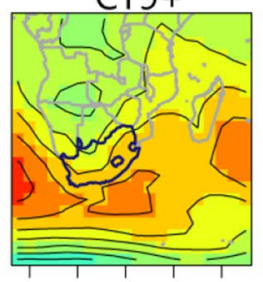

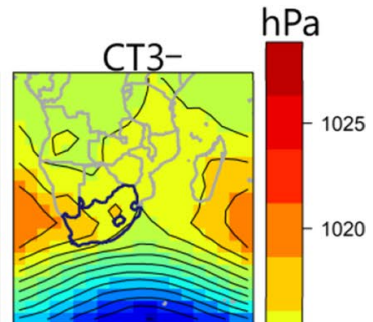



1015

1010


Fig. 3 Circulation types in Africa south of the equator. The CTs that are significantly related to the above-average (below-average) Nino 3.4 index are marked by the red (blue) frames 
Table 1 Correlation coefficient between the Nino 3.4 index and the annual frequency of occurrences, and loadings (amplitude) of the classified CTs for the 1979-2020 period. Bold values showed correlations greater than 0.2 , and $(*)$ shows correlations that are statistically significant at a $95 \%$ confidence level based on the Kendall-Tau test. For the amplitude, the coefficient is written only for the phase directly related to the above-average Nino 3.4 index

\begin{tabular}{|c|c|c|}
\hline $\mathrm{CT}$ & Frequency & Amplitude \\
\hline $\mathrm{CT} 1+$ & 0.26 & 0.30 \\
\hline CT1 - & -0.23 & \\
\hline $\mathrm{CT} 2+$ & -0.11 & \\
\hline $\mathrm{CT} 2-$ & -0.19 & 0.08 \\
\hline CT3+ & -0.24 & \\
\hline CT3 - & 0.17 & 0.21 \\
\hline CT4+ & 0.13 & 0.15 \\
\hline CT4 - & -0.03 & \\
\hline CT5+ & $-0.41 *$ & \\
\hline CT5 - & $0.31 *$ & $0.40 *$ \\
\hline CT6+ & 0.11 & 0.03 \\
\hline CT6 - & -0.08 & \\
\hline $\mathrm{CT} 7+$ & 0.22 & 0.17 \\
\hline CT7 - & -0.05 & \\
\hline $\mathrm{CT} 8+$ & -0.23 & \\
\hline CT8 - & 0.05 & 0.1 \\
\hline CT9+ & -0.10 & \\
\hline CT9- & 0.1 & 0.17 \\
\hline
\end{tabular}

sets is 0.7. NCEP-NCAR data set will be used for further analysis given that it provides the complete set of other climatic variables of interest in this work and also due to the longest available period of the data sets.

\subsection{The relationship between ENSO and the classified circulation types in Africa south of the equator}

By retaining 9 components, $18 \mathrm{CTs}$ were classified and Fig. 3 shows the CTs. By visual comparison, the CTs are similar to the patterns of atmospheric circulation obtained with SOM on SLP (e.g., Wolski et al. 2018). Table 1 presents the correlation coefficient between the Nino 3.4 index, and the loadings (amplitude) of the retained components and the annual frequency of occurrence of the CTs clustered from the components, for the 1979-2020 period. For clarity, for the amplitude in Table 1, the (positive) correlation coefficient is written only for the phase directly related to the above-average Nino 3.4 index, implying that El Niño rather constrains the other phase. For the analysis period, at lag 0 , a statistically significant relationship was found only between the Nino 3.4 index and the amplitude and frequency of Type 5 (CT5 +/CT5 -). The above-average Nino 3.4 index (El Niño) is significantly related to CT5 - and the below-average Nino 3.4 index is significantly related to $\mathrm{CT} 5+$. Both CTs that are statistically related to El Niño and La Niña are highlighted in Fig. 3 by the red and blue frames, respectively. A physical justification of the relationship between CT5 - and El Niño is that during El Niño the south Indian Ocean high-pressure is weakened (Cook 2000) and the tropical Indian Ocean $\left(20^{\circ} \mathrm{S}-20^{\circ} \mathrm{N}\right)$ is anomalously warm (i.e., enhanced cyclonic activity) (Klein et al. 1999). From Fig. 3, these features are evident in CT5 -. The dominant period of CT5 - is DJFM (Appendix Fig. 11) when according to Manatsa et al. (2015) the relationship between ENSO and southern African precipitation is strongest. While CT5 + is not dominant during DJFM (Appendix Fig. 11), a strong dynamical linkage was observed between CT5 + and CT6 - that is a dominant wet DJFM pattern. CT6 - is associated with a stronger anti-cyclonic circulation at the western branch of the South Indian Ocean high-pressure, and widespread southeasterly fluxes in the southwest Indian Ocean (not shown) as observed during strong La Niña events. The dynamical linkage implied that during DJFM, the occurrence of CT5 + precedes CT6 - and this could be because both CTs feature strong anti-cyclonic circulation at the western branch of the South Indian Ocean high-pressure.

From Fig. 4 and Fig. 5, under CT5 -, regardless of the weakening of southeast winds under the activities of the South Indian Ocean high-pressure, the ridging of the South Atlantic Ocean high-pressure, south of South Africa, drives abundant moisture from the warm southwest Indian Ocean into the eastern regions of southern Africa. This results in enhanced rainfall at the eastern coastal regions of South Africa (e.g., Ndarana et al. 2018). The western regions are dry since the moist southeast winds penetrate less into the western regions.

Under CT5 +, the wind at the eastern coastal region of South Africa is predominantly westerly. Thus, large parts of South Africa are dry since moisture advection by southeast winds is weakened. Also, anticyclonic activity dominates in large parts of the southwest Indian Ocean. However, south of South Africa, westerlies prevail, so that the southwestern regions of the Western Cape are wet under the activity of cold fronts. Table 2 shows that in a lag of up to 2-3 months, El Niño can enhance the amplitude of CT5 -.

From Table 1, even though the relationships are not statistically significant at a $95 \%$ confidence level, El Niño might be related to the amplitude of CT1 + and CT3 while La Niña might exhibit some relationship with the amplitude of their inverse phases. It is also interesting that $\mathrm{CT} 1+$ is close to the overall mean pattern of atmospheric circulation in the study region (Appendix Fig. 10). According to Tyson and Preston-Whyte (2000), El Niño can account for about $30 \%$ of rainfall variability in southern Africa. Generally, CT1 + tends to be dominant during austral winter (Appendix Fig. 11) and overlaps with the active periods of all the classified CTs. Thus, a phenomenon such as ENSO that modulates it will have a significant influence on the overall patterns of atmospheric circulation in southern Africa. From Table 2, from a lag of up to 1 month, El Niño significantly enhances 


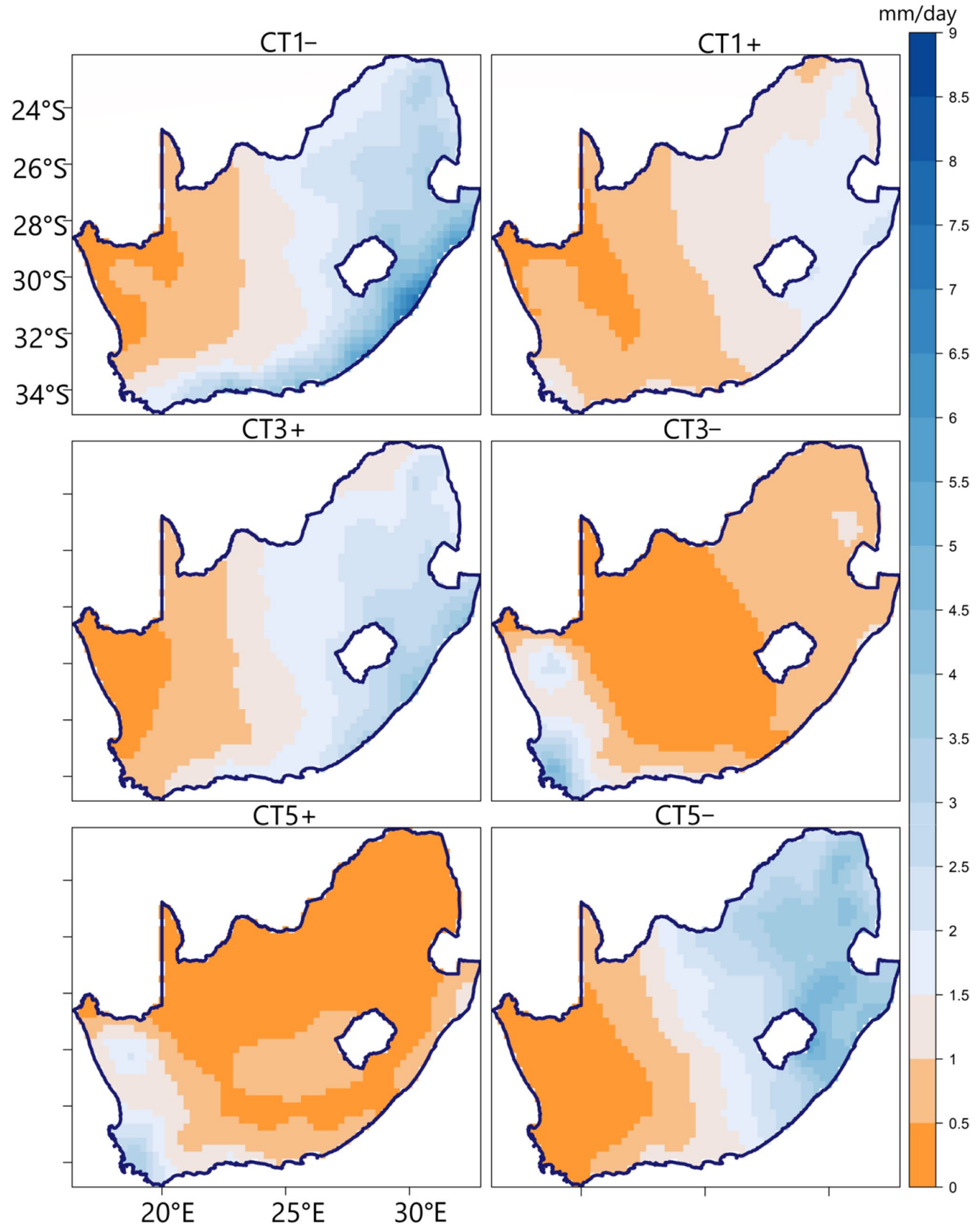

Fig. 4 Rainfall composites of the CTs that their amplitudes are significantly modulated by the ENSO signal. Rainfall composites of CTs constrained (enhanced) by the El Niño signal are placed at the left (right) panels 

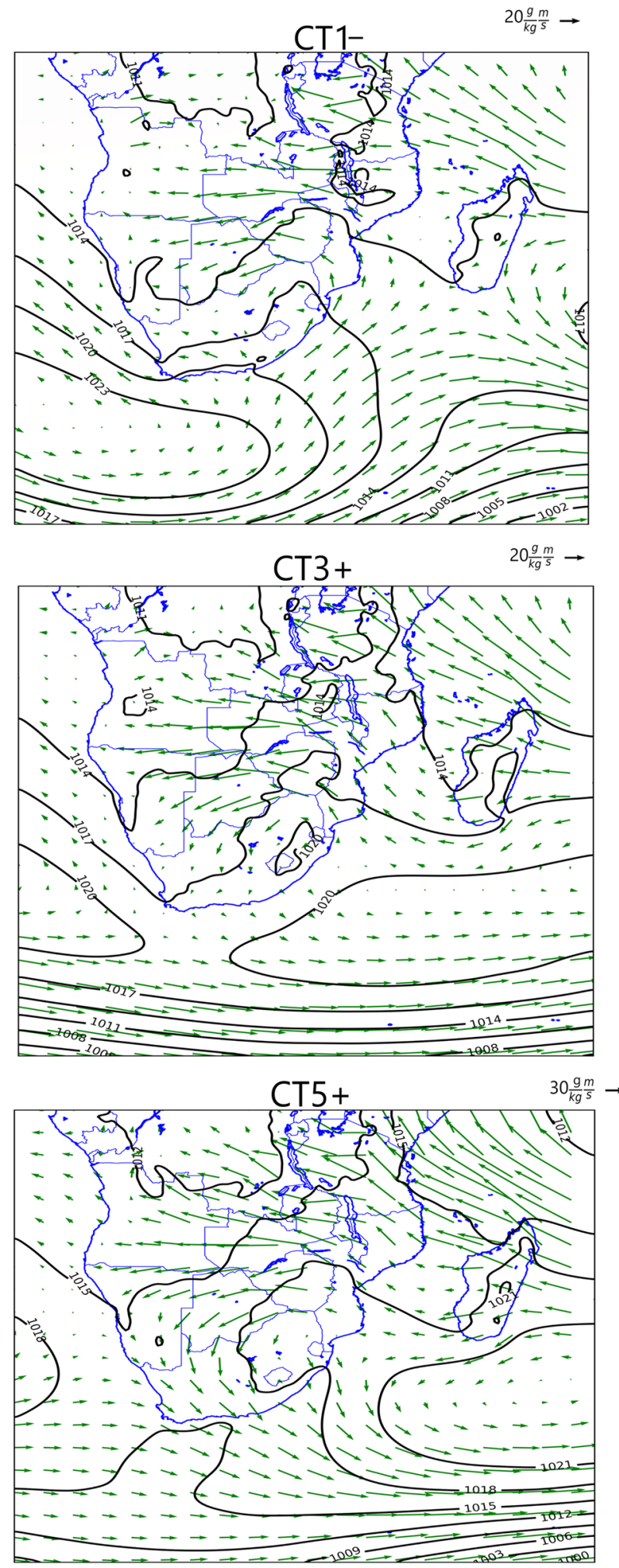

Fig. 5 Same as Fig. 4 but for SLP, and moisture flux composites at $850 \mathrm{hPa}$. Contour is SLP and contour interval is $3 \mathrm{hPa}$. Green vectors are moisture flux at $850 \mathrm{hPa}$. The vector scale is written on the map.
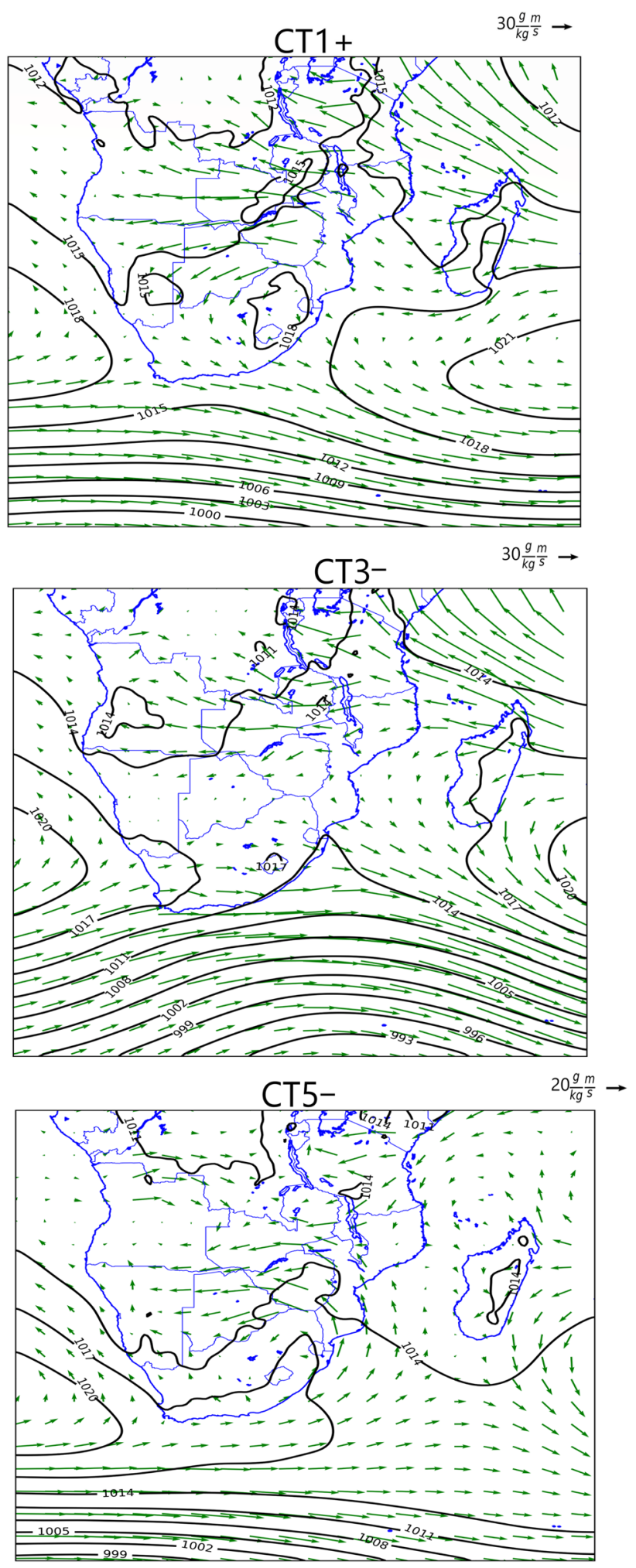

Composites constrained (enhanced) by the El Niño signal are placed at the left (right) panels 
Table 2 Lagged correlations of up to 3 months showing the influence of ENSO on the DJFM amplitude of the types written in bold in Table 1. (*) shows correlations that are statistically significant at a 95\% confidence level based on the Kendall-Tau test

\begin{tabular}{llll}
\hline Type & 1-month lag & 2-month lag & 3-month lag \\
\hline $1(+)$ & $0.40^{*}$ & $0.36^{*}$ & 0.30 \\
$3(+)$ & $-0.41^{*}$ & $-0.32^{*}$ & -0.24 \\
$5(-)$ & 0.28 & $0.31^{*}$ & $0.31^{*}$ \\
\hline
\end{tabular}

the amplitude of $\mathrm{CT} 1+$. The physical justification of the relationship between CT1 + and El Niño can be because El Niño increases surface pressure over landmasses in southern Africa (Hoell et al. 2015) and also weakens easterly moisture fluxes. These features-i.e., the dominance of a high-pressure system over southern African landmasses and westerly moisture fluxes across the Agulhas current-are evident during CT1 + (Fig. 3 and Fig. 5). As a result, CT $1+$ is relatively a dry CT (Fig. 4). Also,
Table 1 indicates that during El Niño, the frequency of occurrence of CT1 + is likely to be enhanced.

CT3 - is the same CT reported in Ibebuchi (2021a) to be significantly related to the negative phase of the Southern Annular Mode (SAM). It is associated with enhanced cyclonic activity and a band of westerlies at the mid-latitudes, and vice versa for its inverse phase (Fig. 5). While not statistically significant, Table 1 indicates that El Niño might strengthen/constrain CT3 -/CT3 + . According to Wang and Cai (2013), El Niño contributes to the negative SAM and La Niña contributes to the positive SAM. It is also interesting that $\mathrm{CT} 3+$ is close to the austral summer mean pattern of atmospheric circulation in southern Africa (Appendix Fig. 10 and Fig. 11). Thus, its modulation by a phenomenon such as El Niño can impact significantly easterly moisture fluxes in the southwest Indian Ocean. Since generally, CT3 + overlaps with other austral summer patterns, the stronger and persistent anti-cyclonic circulation at the western branch of the South Indian Ocean high-pressure associated with it is necessary to create
Table 3 Anomalies in the frequency of occurrence of the CTs (in days/year) written in bold in Table 1 during strong DJF El Niño, La Niña, and neutral ENSO events. The years are arranged in descending order according to the strength of the El Niño and La Niña signal

\begin{tabular}{|c|c|c|c|c|c|c|c|}
\hline & CT1+ & CT1 - & CT3+ & CT5+ & CT5 - & CT7+ & CT8+ \\
\hline \multicolumn{8}{|l|}{ El Niño } \\
\hline 2016 & -3 & +8 & -16 & -6 & -8 & +5 & -7 \\
\hline 1983 & +27 & -19 & -11 & -6 & +9 & +6 & -5 \\
\hline 1998 & +16 & -4 & +16 & +8 & -14 & 0 & +5 \\
\hline 1992 & +20 & -8 & -41 & +4 & -6 & +4 & -5 \\
\hline 2010 & -19 & +14 & +6 & -2 & -7 & +3 & -5 \\
\hline 1987 & +32 & -8 & -30 & -2 & +14 & +3 & -9 \\
\hline 1988 & -5 & +4 & -39 & +18 & -28 & 0 & +10 \\
\hline 1995 & -34 & +15 & +30 & +22 & -9 & +15 & -6 \\
\hline 2003 & +10 & -14 & -7 & +7 & +10 & +6 & -5 \\
\hline \multicolumn{8}{|c|}{ La Niña } \\
\hline 2011 & -62 & +26 & +26 & +5 & +32 & -15 & +20 \\
\hline 1989 & +14 & -13 & +22 & +9 & -6 & +3 & -3 \\
\hline 2000 & -7 & -6 & +36 & +6 & -15 & +5 & -2 \\
\hline 2008 & -20 & +25 & +10 & +10 & -8 & -8 & +12 \\
\hline 1999 & +10 & -12 & +21 & +11 & -25 & +3 & -7 \\
\hline 2012 & -2 & +10 & -12 & -10 & -2 & +11 & +8 \\
\hline 2018 & +11 & -11 & -18 & +4 & +11 & -9 & -6 \\
\hline \multicolumn{8}{|l|}{ Neutral } \\
\hline 1979 & -18 & -6 & -7 & +12 & -2 & -6 & -11 \\
\hline 1981 & -15 & +17 & +11 & +14 & +8 & -8 & +6 \\
\hline 1982 & +4 & 0 & +1 & -1 & -4 & -2 & -2 \\
\hline 1990 & -18 & +7 & 0 & -7 & 0 & -11 & +1 \\
\hline 1993 & +14 & -10 & +15 & +14 & -6 & -5 & -9 \\
\hline 1994 & -9 & -3 & +29 & +15 & -1 & -4 & -6 \\
\hline 2002 & +14 & -8 & -1 & -6 & -7 & -13 & +4 \\
\hline 2017 & +2 & +1 & -6 & -9 & +16 & -20 & -4 \\
\hline
\end{tabular}


Table 4 Same as Table 3 but for anomalies in the persistence of the CTs (in days/year)

\begin{tabular}{|c|c|c|c|c|c|c|c|}
\hline & CT1 + & CT1 - & CT3+ & CT5+ & CT5 - & CT7+ & CT8+ \\
\hline \multicolumn{8}{|l|}{ El Niño } \\
\hline 2016 & -5 & +1 & -5 & -1 & 0 & 0 & -2 \\
\hline 1983 & +7 & -1 & -4 & -4 & +3 & 0 & -2 \\
\hline 1998 & 0 & +1 & -5 & -1 & 0 & -1 & +3 \\
\hline 1992 & +9 & -2 & -7 & -1 & +2 & 0 & -2 \\
\hline 2010 & -1 & +2 & -4 & -2 & +1 & 0 & -2 \\
\hline 1987 & +10 & -3 & -6 & 0 & +2 & 0 & -3 \\
\hline 1988 & -2 & 0 & -7 & -1 & +1 & -2 & -2 \\
\hline 1995 & +4 & +4 & -4 & -1 & +1 & +1 & -1 \\
\hline 2003 & -8 & -4 & -5 & -1 & 0 & -2 & -2 \\
\hline \multicolumn{8}{|c|}{ La Niña } \\
\hline 2011 & -8 & +4 & +3 & +1 & +3 & -1 & -2 \\
\hline 1989 & +6 & -4 & 0 & +3 & 0 & +4 & -2 \\
\hline 2000 & +7 & -2 & +4 & +1 & -2 & 0 & -2 \\
\hline 2008 & -4 & 0 & +1 & 0 & +1 & -2 & -2 \\
\hline 1999 & +16 & -4 & +1 & +1 & -1 & -1 & -2 \\
\hline 2012 & -3 & +1 & -6 & -2 & -2 & 0 & -2 \\
\hline 2018 & +7 & -3 & -5 & -1 & 0 & -2 & -2 \\
\hline \multicolumn{8}{|l|}{ Neutral } \\
\hline 1979 & -4 & -1 & -2 & -1 & +3 & -2 & -3 \\
\hline 1981 & -2 & 0 & -6 & +1 & -1 & -1 & -3 \\
\hline 1982 & +10 & -2 & -5 & 0 & -1 & -1 & -3 \\
\hline 1990 & +12 & -2 & +1 & -3 & -2 & -1 & -3 \\
\hline 1993 & 0 & -3 & -4 & -1 & -2 & -2 & -3 \\
\hline 1994 & -6 & -1 & +3 & -2 & -3 & -2 & -3 \\
\hline 2002 & -3 & -3 & -5 & -1 & 0 & -1 & -2 \\
\hline 2017 & +22 & +5 & +3 & -2 & -1 & 0 & -2 \\
\hline
\end{tabular}

the austral summer atmospheric condition, favorable for onshore moisture advection during the active period of other (wet) CTs. From Fig. 4, CT3 + is generally wet in South Africa except for the regions with the Mediterranean type of climate that are wet under CT3 - From Table 2, in a lag of at least 1 month, El Niño significantly constrains the amplitude of CT3 + .

Generally, except for Type 5, from Fig. 4 and Fig. 5, Table 1 and Table 2, El Niño enhances (constrains) the amplitude and frequency of occurrence of dry (wet) CTs associated with westerly (easterly) fluxes over the southwest Indian Ocean (specifically the Agulhas current). However, the statistically significant relationship between El Niño and CT5 - from Table 1 might suggest that CT5 - plays the foundation role in how El Niño modulates the other CTs. Since CT5 - indicates a weaker South Indian Ocean highpressure and enhanced cyclonic activity in the southwest Indian Ocean that during strong El Niño events can favor weakening of onshore moisture fluxes by southeasterlies. When the moistening of the boundary layer in the southern African landmasses is weakened relative to the ambient atmosphere, then deep convection (vertical motion) can be relatively constrained.

\subsection{Anomalies in the circulation types modulated by ENSO during strong and neutral ENSO events}

Table 3 and Table 4 show the anomalies in the frequency of occurrence and persistence of the CTs that were highlighted from the correlation analysis in Table 1, during strong ENSO events and ENSO neutral phase. It can be observed that generally, there is no definite pattern on how ENSO influences the frequency distribution of the CTs. This fits the idea that ENSO is not always well related to rainfall variability in southern Africa. However, from Table 3, there is the indication that strong El Niño events might enhance the frequency of occurrence of CT1+. Also, generally, during strong El Niño (La Niña) events, the frequency of occurrence and persistence of CT3 + are likely to be constrained (enhanced). The persistence of CT5 - is equally likely to be enhanced (constrained) during strong El Niño (La Niña) events. It can be observed 
A)

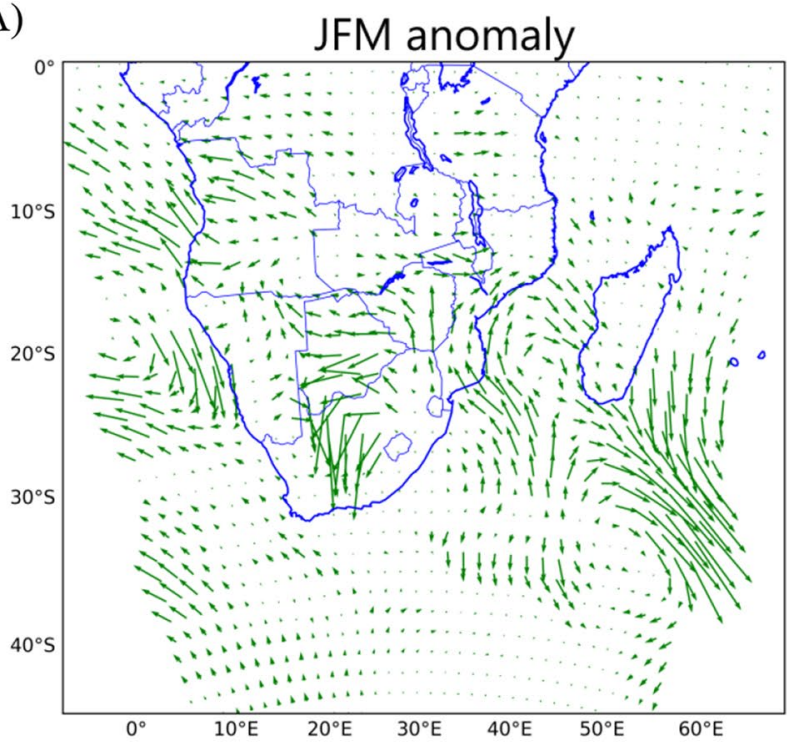

B)

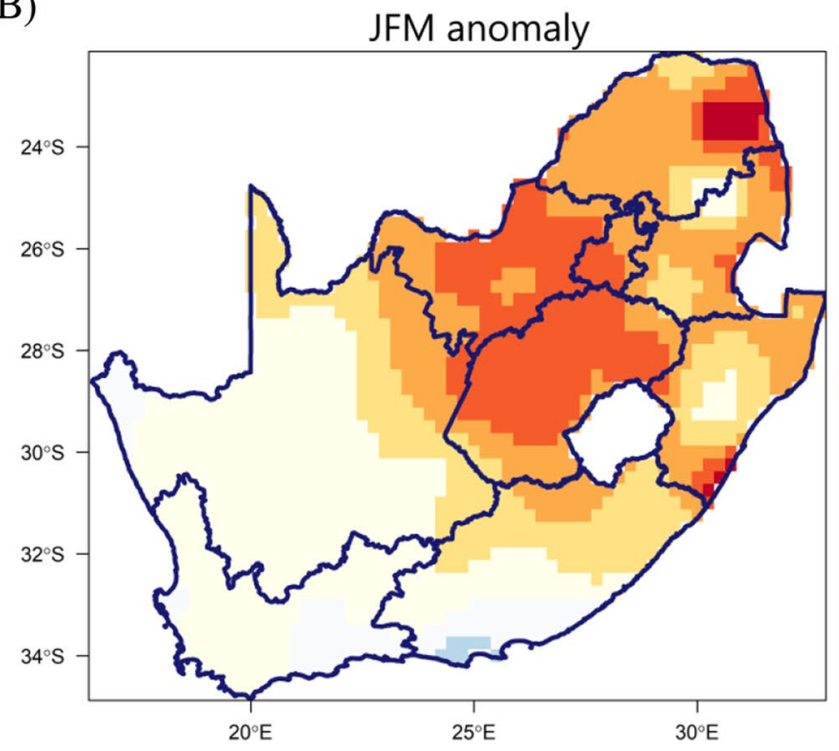



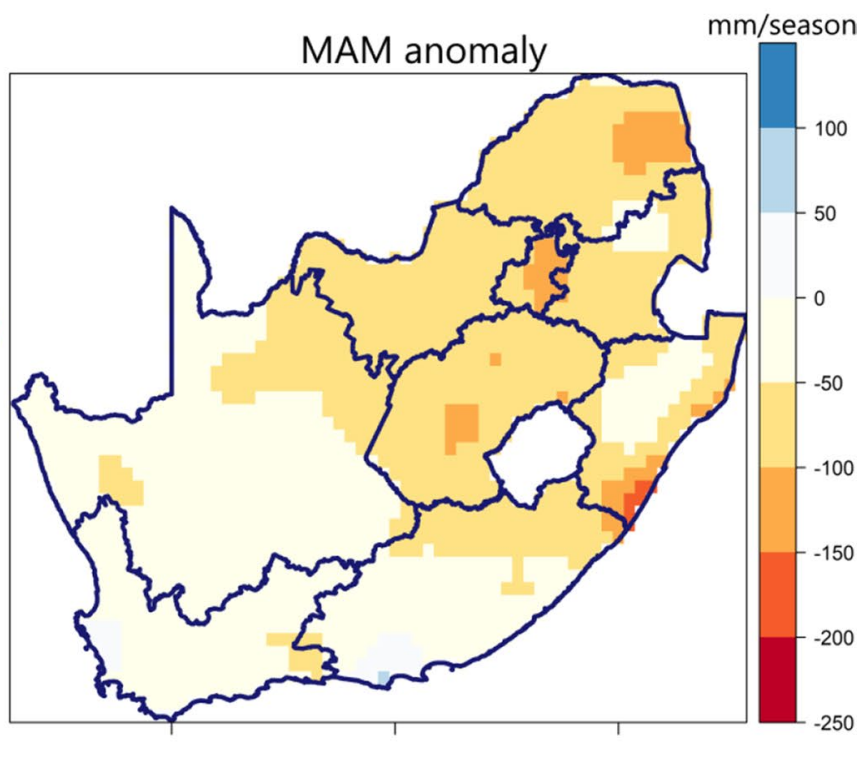

Fig. 6 Anomalies of moisture flux (A) and rainfall (B) for the JFM and MAM seasons when CT5 - occurred during 1992. Anomalies in (A) are calculated with respect to the JFM and MAM climatology of CT5 -

from Table 3 that during the 1992 strong El Niño event, there is a robust decrease in the frequency of occurrence of CT3 + . This might have significantly contributed to the severe drought episode witnessed during the 1992 strong El Niño event.

It was also found that during the 1992 El Niño event, regardless of the increase in the persistence of CT5 -, its frequency of occurrence and circulation features seem to be constrained. Physically, this was examined in Fig. 6 based on anomalies in moisture fluxes at $850 \mathrm{hPa}$ during the periods CT5 - occurred in 1992 for the JFM and
MAM seasons, and the resultant effect on precipitation anomaly in South Africa in the 1992 JFM and MAM months. The anomaly in moisture flux is calculated as the difference between the JFM climatology of CT5 from 1979-2020 and the JFM climatology of CT5 - during 1992 (the same holds for MAM). It can be seen that unlike the climatology of CT5 - in Fig. 5, in Fig. 6A, southeasterly fluxes in the southwest Indian Ocean tend to be southerly and southwest during the 1992 El Niño season. Thus, under CT5 -, onshore moisture advection by southeast winds onto the South Africa Plateau was 


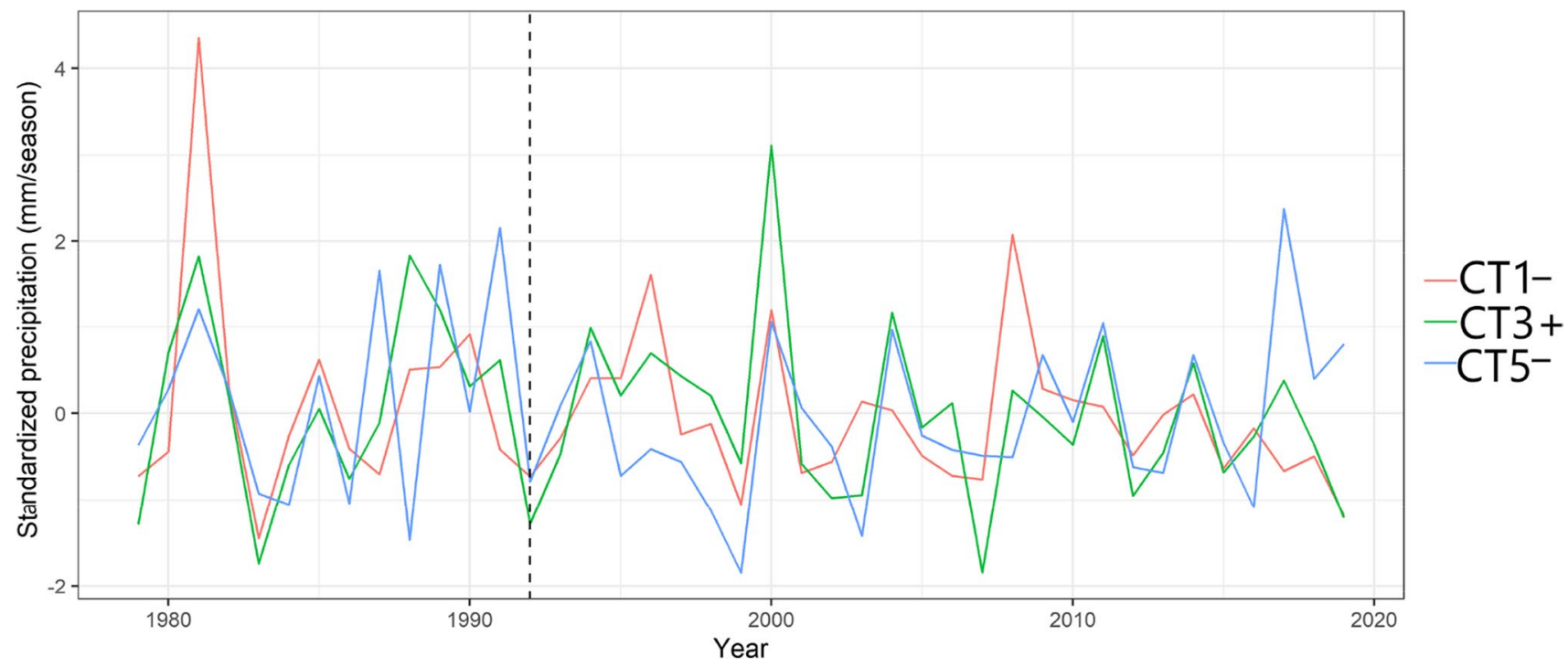

Fig. 7 Time series of precipitation for the dominant austral summer wet CTs modulated by the ENSO signal. The time series is for the 1979-2019 period and the Y-axis is the $\mathrm{z}$-score standardized values

relatively weakened during the $1992 \mathrm{El}$ Niño event. This was more robust in the JFM season when the deficit in moisture fluxes in eastern parts of South Africa was relatively higher compared to the MAM season. Figure $6 \mathrm{~B}$ shows that during these seasons, a significant rainfall deficit (i.e., $<50 \mathrm{~mm} / \mathrm{season}$ ) occurred in the eastern and northeastern parts of South Africa. The western regions were relatively less dry; this might be attributed to the northerly wind that is evident in parts of the western regions (c.f. Fig. 6A). Northerly winds are also evident during CT1 + and CT5 + (Fig. 5) that the 1992 El Niño event enhanced their frequency of occurrence. From Fig. 7, the wet patterns related to ENSO of JFM annual precipitation totals. The vertical dashed black line highlights the year 1992

recorded deficit in JFM seasonal rainfall totals averaged over South Africa during the 1992 El Niño event.

\subsection{The influence of radiative heating on the CT significantly related to El Niño under the ssp585 scenario}

Using two GCMs that simulated well the mean shape of CT5 - (Fig. 8) that is significantly related to variations of ENSO, the influence of radiative heating on the spatial pressure field of CT5 - was investigated under the ssp585 scenario. Though the changes as shown in Fig. 9 is subjected to intermodel uncertainty, there is a model agreement on (i) pressure
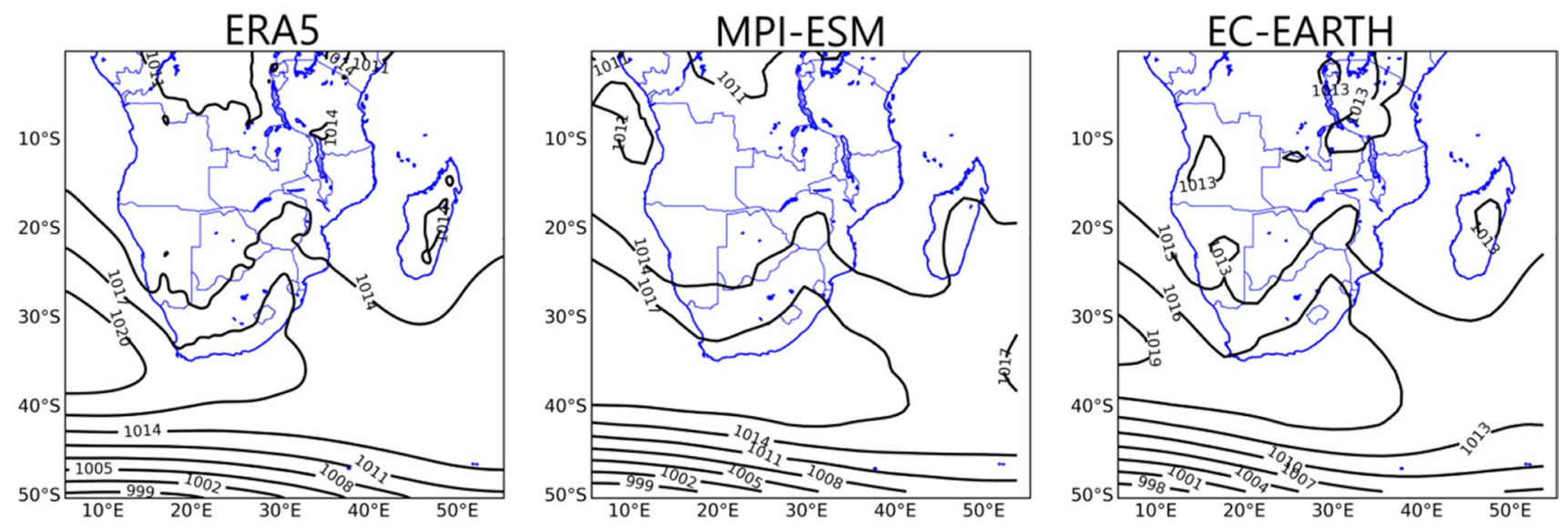

Fig. 8 Composite of CT5 - from NCEP-NCAR and as simulated from the MPI-ESM and EC-EARTH CMIP6 GCMs for the 1979-2014 period. The Contour interval is $3 \mathrm{hPa}$ 
A)

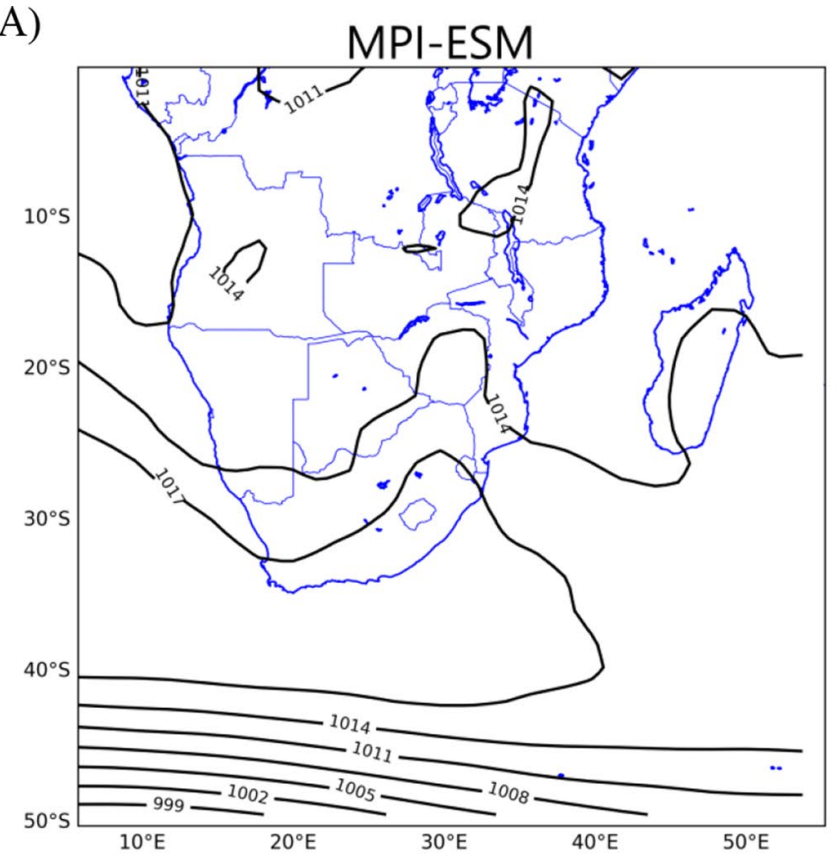

B)

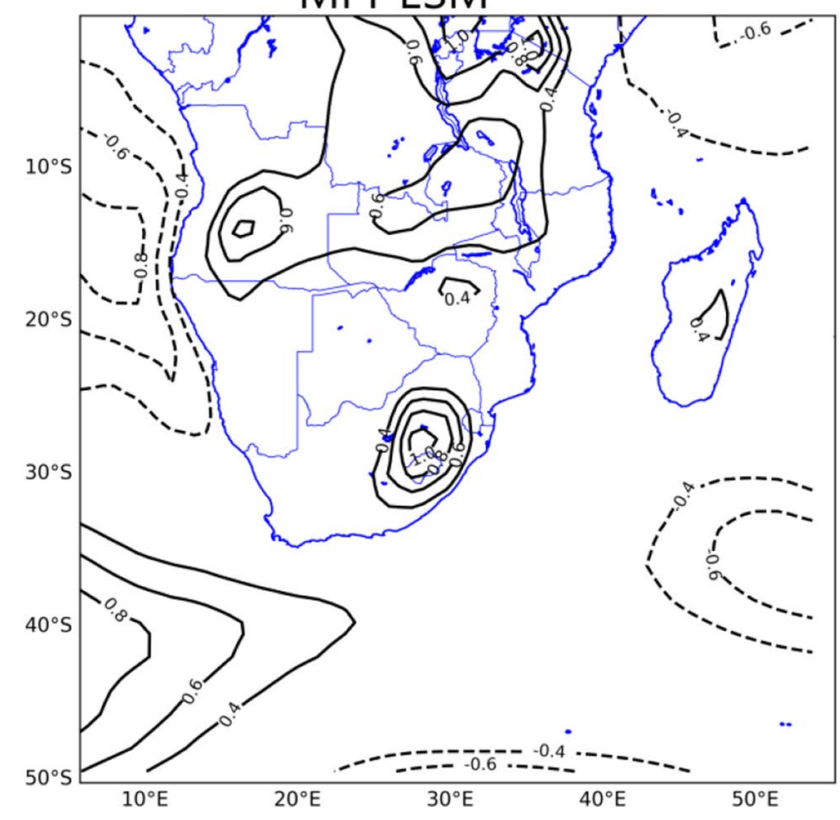

Fig. 9 Composites of CT5 - as simulated by the GCMs under the ssp585 scenario for the 1965-2100 period (A), and the difference between the spatial field of CT5 - as simulated in the historical experiment (1979-2014) and the ssp585 scenario (1965-2100), i.e.,

increase adjacent to the southwestern parts of South Africa (ii) and increase in subsidence (i.e., anomalous anticyclone) at the eastern coastal regions of South Africa, and landmasses from $20^{\circ} \mathrm{S}$ equatorward, under the synoptic state of CT5 -. A possible explanation for the increase in subsidence at the coastal


ssp585 scenario minus historical experiment (B). The contour interval is $3 \mathrm{hPa}$ for $\mathbf{A}$ and $0.2 \mathrm{hPa}$ for $\mathbf{B}$. Only statistically significant values are plotted in (B) based on the permutation test

eastern regions of South Africa under CT5 - can be inferred from MPI-ESM that simulated equally an increase in cyclonic activity at the western branch of the South Indian Ocean highpressure. Further deepening of cyclonic activity in the southwest Indian Ocean under CT5 - might constrain the rate at which 
southeasterly moisture fluxes are advected onto the South Africa plateau and this will, in turn, decrease the rate at which the boundary layer is moistened relative to the ambient atmosphere, resulting to the possible weakening of vertical motion.

\section{Discussion}

According to Gray and Sheaffer (1991), teleconnections can alter regional atmospheric circulation patterns. In the regional context of southern Africa, studies by Cook (2000), Reason and Jagadheesha (2005), Hoell et al. (2015), and Pinault (2018) indicated that El Niño signal can modulate the regional fluxes of moisture advected onto the southern Africa plateau. This can be related both to the weakening of the Mascarene high, and the Rossby waves excited due to changes in tropical Indo-Pacific convection. Klein et al. (1999) also noted that anomalous warming (enhanced cyclonic activity) of the tropical Indian Ocean $\left(20^{\circ} \mathrm{S}-20^{\circ} \mathrm{N}\right)$ are among the El Niño signals in the Indian Ocean.

Using the NCEP-NCAR reanalysis data set, this study examined CTs in Africa south of the equator that can be modulated by the ENSO signal. It should be equally noted that in previous classifications (e.g., Ibebuchi 2021a), the output of the CT classification in this work was reproduced using ERA5 reanalysis (Hersbach et al. 2020) which is closer to reality (e.g., Gleixner et al. 2020). Thus, both data sets represent well the underlying physics in atmospheric circulations in Africa south of the equator.

The synoptic features of CT5 - found in this study to be significantly related to El Niño are in line with the synoptic conditions during El Niño from the aforementioned works of literature. These include (i) weaker state of the south Indian Ocean high-pressure and (ii) enhanced cyclonic activity in the (tropical) south Indian Ocean. CT5 - appears to be the central CT through which El Niño controls other patterns of atmospheric circulation in southern Africa. During strong El Niño events, its amplitude and persistence might be expected to increase and this implies a further weakening of the Mascarene high and the associating fluxes of southeasterlies. These results in the enhancement of CT1 + which is the overall climatology of atmospheric circulation in southern Africa associated with anticyclonic activity over the southern Africa landmasses. The result is in line with the report by Hoell et al. (2015) that El Niño weakens vertical motion over southern Africa.

During the 1992 strong El Niño event, it was found that the El Niño signal could have caused a robust decrease in the frequency of occurrence of CT3+ which is a wet CT, and the austral summer climatology of atmospheric circulation in southern Africa that favors easterly moisture fluxes from the southwest Indian Ocean. Also, during the 1992 El Niño event, the anomalies in CT5 - revealed that southeast winds were adjusted to southerly and southwest winds. Thus, less moisture driven by the South
Atlantic Ocean high-pressure penetrated the eastern regions of South Africa. This could have contributed to the anomalous dry conditions (mainly in the eastern parts) during the 1992 wet seasons.

Relative to 1992, stronger El Niño events were equally recorded in 2016, 1998, and 1983. According to Rouault and Richard (2005), 1983 and 1992 are among the years with the most severe droughts at the 6-month time scale for the summer rainfall region of South Africa. During 1983, a similar scenario as in 1992 was observed which included a decrease (increase) in the frequency of occurrence and persistence of $\mathrm{CT} 3+(\mathrm{CT} 1+)$. However, despite the strong El Niño signal during 1998, a robust decrease (increase) in the frequency of occurrence and persistence of $\mathrm{CT} 3+(\mathrm{CT} 1+)$ was not observed, which could have contributed to why severe drought of a similar category as of the 1992 episode, failed to materialize (Lyon and Manson 2007). A similar argument can be inferred during the 2016 event. To this end, it should be noted that there have been other drought years in parts of South Africa (e.g., Western Cape) not completely linked to ENSO. Thus, ENSO is not the only climatic driver that can trigger hydrological extremes in South Africa. Variations of the SAM (e.g., Ibebuchi 2021a) and the Subtropical Indian Ocean dipole, coupled with the impact of anthropogenic climate change on atmospheric circulations, can equally be associated with drought episodes in different parts of South Africa.

\section{Conclusions}

Using obliquely rotated T-mode PCA applied to SLP, CTs were classified in Africa south of the equator. CT5 - associated with a weaker state of the south India Ocean high-pressure and enhanced cyclonic activity at the tropical southwest Indian Ocean was found in this paper to be statistically related to El Niño. El Niño enhances the amplitude of CT5 - and this implies weakening of atmospheric conditions associated with stronger anti-cyclonic circulation at the western branch of the Mascarene high, and enhancement of atmospheric conditions that favor westerly winds across the Agulhas current. During the 1992 El Niño event, drought conditions in South Africa might have amplified due to (i) robust decrease in the frequency of occurrence of $\mathrm{CT} 3$ + that favors southeasterly moisture fluxes, advected by the Mascarene high, onto southern Africa, during austral summer (ii) and the modulation of onshore moisture advection by southeast winds, under the activity of the South Atlantic Ocean high-pressure, ridging south of South Africa, under CT5 - . The latter scenario could be a result of the Rossby waves excited in the tropical Indo-Pacific.

Under the ssp585 scenario, from the analyzed climate models, the impact of radiative heating, on CT5 - suggests an increase in subsidence in the eastern parts of South Africa. 


\section{Appendix}

Figures 10, 11

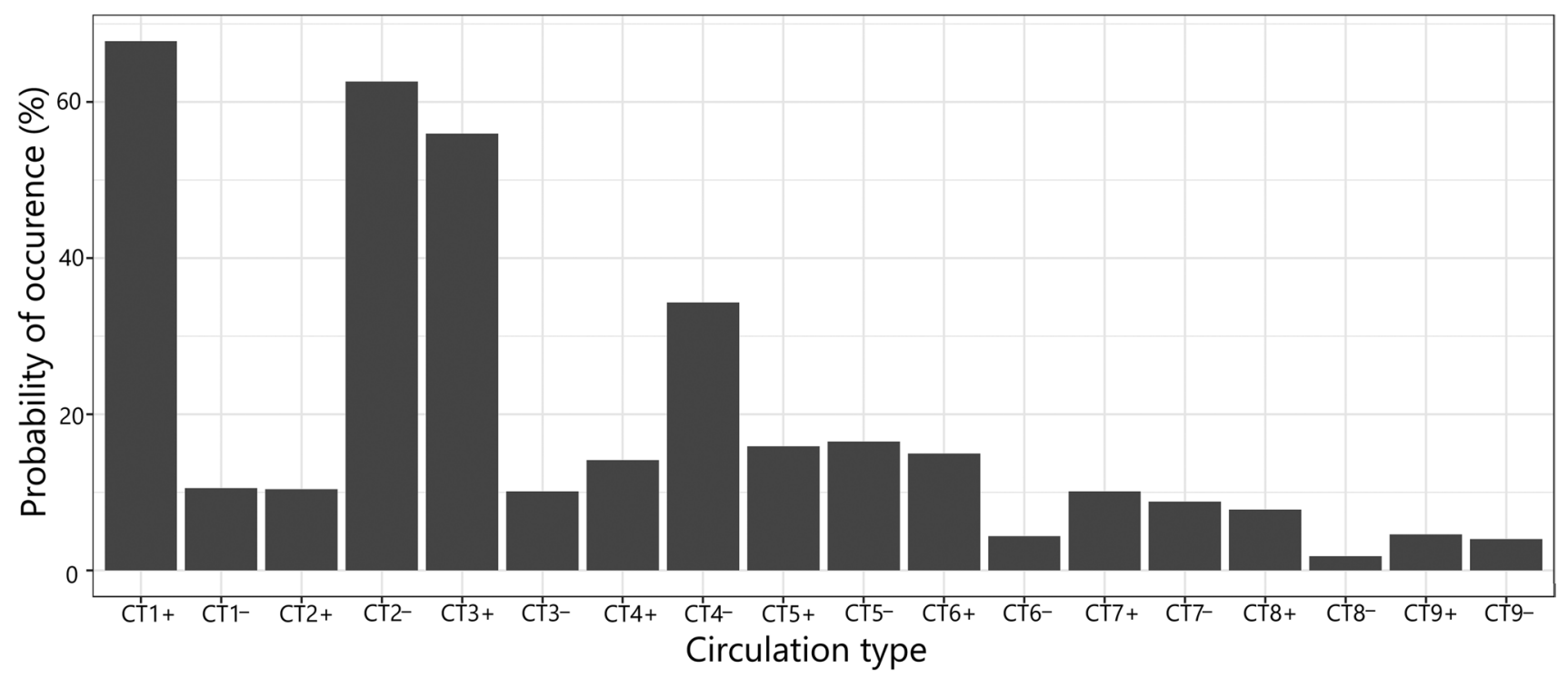

Fig. 10 Probability of occurrence of the CTs in Fig. 3. The probabilities do not add up to $100 \%$ since the classification allows overlapping of the classified variables given the fuzzy/continuous nature of atmospheric circulation patterns. CT1 +, CT2 -, CT3+, and CT4 that are large classes are designated as the dominant or actual occurring states of the atmosphere 

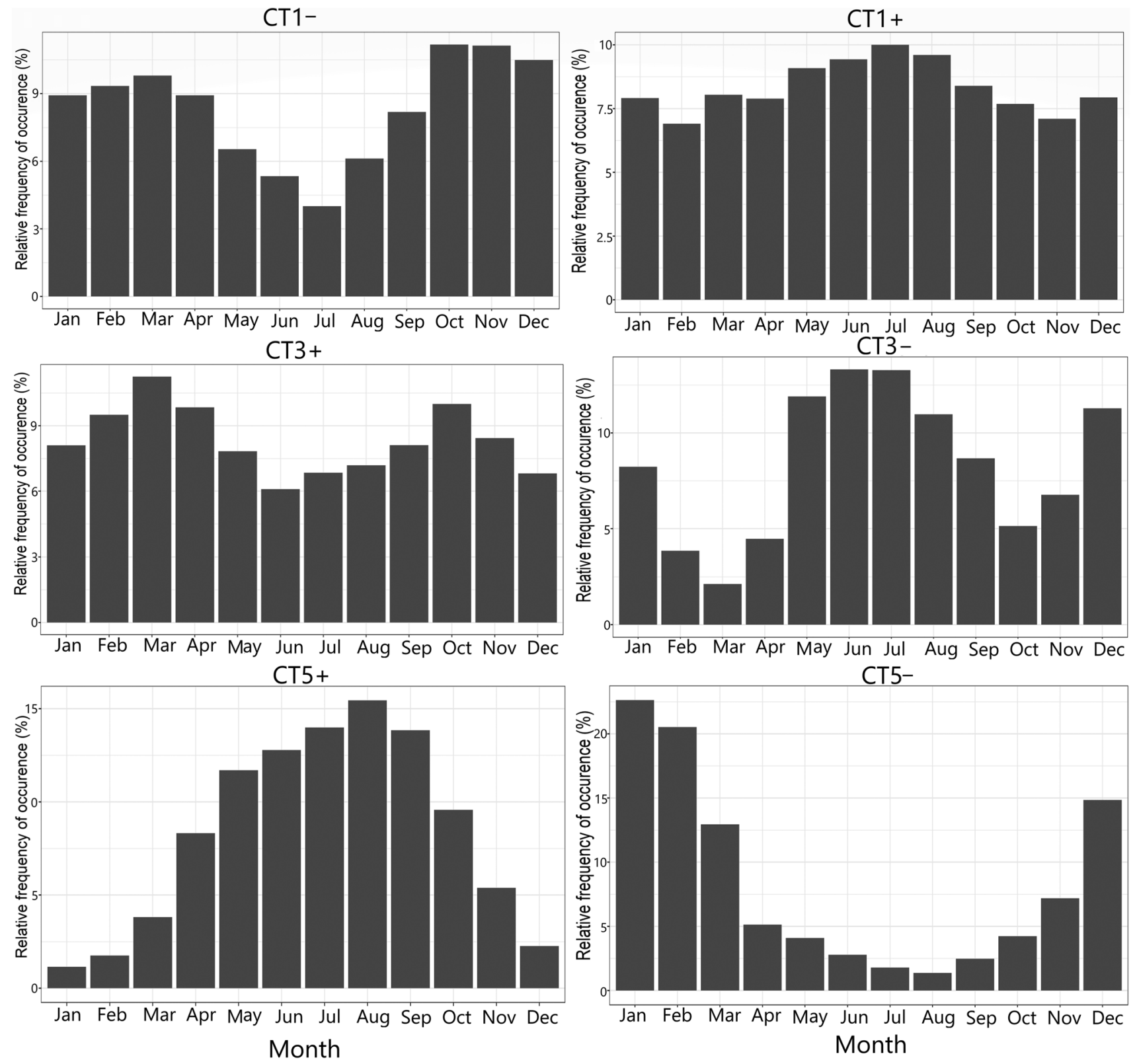

Fig. 11 Annual cycle of the selected CTs in Figs. 4 and 5

Acknowledgements Thanks to NOAA/OAR/ESRL PSL for providing the NCEP-NCAR reanalysis data sets and the CPC gridded precipitation data used in this work. I acknowledge the World Climate Research Programme's Working Group on Coupled Modelling, which is responsible for CMIP, and I thank the climate modeling groups for producing and making available the MPI-ESM and EC-EARTH CMIP6 simulations used in this work.

Funding Open Access funding enabled and organized by Projekt DEAL.

Author contribution Work was designed and executed by Chibuike Chiedozie Ibebuchi.

Data availability The NCEP-NCAR reanalysis and CPC precipitation data sets are available at https://psl.noaa.gov/data/gridded/data.ncep. reanalysis.html. The CMIP6 GCMs is available at https://esgf-data. dkrz.de/projects/esgf-dkrz/.

Code availability $\mathrm{R}$ studio was used for coding the methods as described in the methodology section. The codes are base packages in $\mathrm{R}$ (e.g., the PROMAX routine). 


\section{Declarations}

Ethics approval No human subject is involved in this study and figures belong to the author. The paper is also not under consideration in any Journal.

Consent to participate No human research is used. The author consent this paper to be considered.

Consent for publication The author consent this paper to be published.

Conflict of interest The author declare no competing interests.

Open Access This article is licensed under a Creative Commons Attribution 4.0 International License, which permits use, sharing, adaptation, distribution and reproduction in any medium or format, as long as you give appropriate credit to the original author(s) and the source, provide a link to the Creative Commons licence, and indicate if changes were made. The images or other third party material in this article are included in the article's Creative Commons licence, unless indicated otherwise in a credit line to the material. If material is not included in the article's Creative Commons licence and your intended use is not permitted by statutory regulation or exceeds the permitted use, you will need to obtain permission directly from the copyright holder. To view a copy of this licence, visit http://creativecommons.org/licenses/by/4.0/.

\section{References}

Baudoin M, Vogel C, Nortje Naik M (2017) Living with drought in South Africa: lessons learnt from the recent El Niño drought period. Int J Disaster Risk Reduct 23:128-137. https://doi.org/ 10.1016/j.ijdrr.2017.05.005

Bruwer JJ (1993) Drought policy in the Republic of South Africa. In: Wilhite DA (ed) Drought assessment, management, and planning: theory and case studies. Natural Resource Management and Policy, vol 2.Springer, Boston, MA. https://doi.org/10.1007/9781-4615-3224-8_11

Compagnucci RH, Richman MB (2008) Can principal component analysis provide atmospheric circulation or teleconnection patterns? Int J Climatol 28(6):703-726. https://doi.org/10.1002/joc.1574

Cook KH (2000) The South Indian Convergence Zone and Interannual Rainfall Variability over Southern Africa. J Clim 13(21):3789_ 3804. https://doi.org/10.1175/1520-0442(2000)013<3789:TSICZ $\mathrm{A}>2.0 . \mathrm{CO} ; 2$

Driver P (2014) Rainfall variability over Southern Africa. PhD Thesis, University of Cape Town, South Africa. https://citeseerx.ist.psu. edu/viewdoc/download?doi=10.1.1.913.1020\&rep=rep1\&type $=$ pdf. Accessed 21 Mar 2021

Engelbrecht CJ, Landman WA (2016) Interannual variability of seasonal rainfall over the Cape south coast of South Africa and synoptic type association. Clim Dyn 47(1-2):295-313. https://doi. org/10.1007/s00382-015-2836-2

Engelbrecht CJ, Landman WA, Engelbrecht FA, Malherbe J (2015) A synoptic decomposition of rainfall over the Cape south coast of South Africa. Clim Dyn 44(9-10):2589-2607. https://doi.org/10. 1007/s00382-014-2230-5

Glantz M, Betsill M, Crandall K(1997) Food security in Southern Africa: Assessing the use and value of ENSO information. Boulder, Environmental and Societal Impacts Groups, National Center for Atmospheric Research

Gleixner S, Demissie T, Diro TG (2020) Did ERA5 improve temperature and precipitation reanalysis over East Africa? Atmosphere 11(9):996. https://doi.org/10.3390/atmos11090996
Gong X, Richman MB (1995) On the application of cluster analysis to growing season precipitation data in North America East of the Rockies. J Clim 8(4):897-931. https://doi.org/10.1175/15200442(1995)008<0897:OTAOCA > 2.0.CO;2

Gray WM, Sheaffer JD (1991) El Niño and QBO influences on tropical cyclone activity. In: Glantz MH, Katz RW, Nicholls N (eds) Teleconnections linking worldwide climate anomalies: scientific basis and social impacts.Cambridge University Press: Cambridge

Hersbach H, Bell B, Berrisford P, Hirahara S, Nicolas J, Radu R, Simmons A, Abellan X, Soci C, Bechtold P et al (2020) The ERA5 global reanalysis. Q J R Meteorol Soc 146(730):1999-2049

Hewitson B, Crane R (2002) Self-organizing maps: Applications to synoptic climatology. Clim Res 22(1):13-26. https://doi.org/10. 3354/cr022013

Hoell A, Funk C, Magadzire T, Zinke J, Husak G (2015) El NiñoSouthern Oscillation diversity and Southern Africa teleconnections during Austral Summer. Clim Dyn 45(5):1583-1599. https:// doi.org/10.1007/s00382-014-2414-z

Ibebuchi CC (2021a) On the relationship between circulation patterns, the Southern Annular Mode, and rainfall variability in Western Cape. Atmosphere 12(6):753. https://doi.org/10.3390/atmos12060 753

Ibebuchi CC (2021b) Circulation pattern controls of wet days and dry days in Free State, South Africa. Meteorol Atmos Phys 1-12. https://doi.org/10.1007/s00703-021-00822-0

IPCC (2013) The physical science basis. In: Stocker TF, Qin D, Plattner GK, Tignor M, Allen SK, Boschung J, Nauels A, Xia Y, Bex V, Midgley PM (eds) Contribution of working group I to the fifth assessment report of the intergovernmental panel on climate change. Cambridge University Press, Cambridge,pp 1535. https:// doi.org/10.1017/CBO9781107415324

Jones WP (1999) First- and second-order conservative remapping schemes for grids in spherical coordinates. Mon Wea Rev 127(9):2204-2210. https://doi.org/10.1175/1520-0493(1999) 127<2204:FASOCR>2.0.CO;2

Jury MR, Mc Queen C, Levey K (1994) SOI and QBO signals in the African region. Theor Appl Climatol 50:103-115. https://doi.org/ 10.1007/BF00864907

Kalnay E et al (1996) The NCEP/NCAR 40-year reanalysis project. Bull Amer Meteor Soc 77(3):437-472. https://doi.org/10.1175/ 1520-477(1996)077<0437:TNYRP > 2.0.CO;2

Kendall MG (1975) Rank correlation methods. 4th Edition, Charles Griffin, London

Kidson JW (1997) The utility of surface and upper air data in synoptic climatological specification of surface climatic variables. Int $\mathbf{J}$ Climatol 17(4):399-414. https://doi.org/10.1002/(SICI)10970088(19970330)17:4<399::AID-JOC108>3.0.CO;2-M

Klein SA, Soden BJ, Lau C (1999) Remote sea surface temperature variations during ENSO: evidence for a tropical atmospheric bridge. J Clim 12(4):917-932. https://doi.org/10.1175/1520-0442(1999) $012<0917$ :RSSTVD $>2.0 . \mathrm{CO} ; 2$

Lennard C, Hegerl G (2015) Relating changes in synoptic circulation to the surface rainfall response using self-organising maps. Clim Dyn 44(3/4):861-879. https://doi.org/10.1007/s00382-014-2169-6

Lyon B, Manson S (2007) The 1997-98 Summer rainfall season in Southern Africa. Part I: Observations. J Clim 20(20):5134-5148. https://doi.org/10.1175/JCLI4225.1

Mann HB (1945) Non-parametric tests against trend. Econometrica 13(3):245-259

Manatsa D, Mushore T, Lenouo A (2015) Improved predictability of droughts over southern Africa using the standardized precipitation evapotranspiration index and ENSO. Theor Appl Climatol 127:259-274. https://doi.org/10.1007/s00704-015-1632-6

Mason SJ, Tyson PD (2000) The occurrence and predictability of drought over southern Africa. In Wilhite DA (ed) Drought, vol 1: a global assessment. Routledge, New York, pp. 113-124 
Ndarana T, Bopape M, Waugh D, Dyson L (2018) The influence of lower stratosphere on ridging Atlantic Ocean Anticyclone over South Africa. J Clim 31(15):6175-6187. https://doi.org/10.1175/ JCLI-D-17-0832.1

Ninomiya K (2008) Similarities and differences among the South Indian Ocean convergence zone, North American convergence zone, and other subtropical convergence zones simulated using an AGCM. J Meteorol Soc Jpn 86(1):141-165. https://doi.org/ $10.2151 / \mathrm{jmsj} .86 .141$

North G, Bell T, Cahalan FR, Moeng FJ (1982) Sampling errors in the estimation of empirical orthogonal functions. Mon Wea Rev 110(7):699-706. https://doi.org/10.1175/1520-0493(1982)110< 0699:SEITEO>2.0.CO;2

Odoulami RC, Wolski P, New M (2020) A SOM-based analysis of the drivers of the 2015-2017 Western Cape drought in South Africa. Int J Climatol 41(S1):E1518-E1530. https://doi.org/10.1002/joc. 6785

Reason CJC, Mulenga H (1999) Relationships between South African rainfall and SST anomalies in the southwest Indian Ocean. Int J Climatol 19:1651-1673. https://doi.org/10.1002/(SICI)10970088(199912)19:15<1651::AID-JOC439>3.0.CO;2-U

Pinault JL (2018) The anticipation of the ENSO: what resonantly forced baroclinic waves can teach us (Part II). J Mar Sci Eng 6:63. https://doi.org/10.3390/jmse6020063

Preisendorfer RW, Zwiers FW, Barnett TP (1981) Foundations of principal component selection rules. Scripps Institute of Oceanography, La Jolla, California, SIO Ref. Series 81-4 (NTIS PB); 83-146613

Reason CJC, Allan RJ, Lindesay JA, Ansell TJ (2000) ENSO and climatic signals across the Indian Ocean basin in the global context: Part I, interannual composite patterns. Int J Climatol 20(11):1285-1327. https://doi.org/10.1002/1097-0088(200009) 20:11<1285::AID-JOC536>3.0.CO;2-R

Reason CJC, Hachigonta S, Phaladi RF (2005) Interannual variability in rainy season characteristics over the Limpopo Region of Southern Africa. Int J Climatol 25(14):1835-1853. https://doi. org/10.1002/joc. 1228

Reason CJC, Jagadheesha D (2005) A model investigation of recent ENSO impacts over southern Africa. Meteor Atmos Phys 89(1):181-205. https://doi.org/10.1007/s00703-005-0128-9

Richman MB (1981) obliquely rotated Principal Components: an improved meteorological map typing technique? J Appl Meteorol 20(10):1145-1159. https://doi.org/10.1175/1520-0450(1981) $020<1145$ :ORPCAI $>2.0 . \mathrm{CO} ; 2$
Richman MB, Lamb PJ (1985) Climatic pattern analysis of three and seven-day summer rainfall in the Central United States: some methodological considerations and regionalization. J Climate Appl Meteor 24(12):1325-1343. https://doi.org/10.1175/15200450(1985)024<1325:CPAOTA > 2.0.CO;2

Richman MB (1986) Rotation of Principal Components. J Climatol 6(3):293-335. https://doi.org/10.1002/joc.3370060305

Richman MB, Gong X (1999) Relationships between the definition of the hyperplane width to the fidelity of principal component loadings patterns. J Clim 12(6):1557-1576. https://doi.org/10.1175/ 1520-0442(1999)012<1557:RBTDOT > 2.0.CO;2

Rouault M, Richard Y (2005) Intensity and spatial extension of drought in South Africa at different time scales. Geophys Res Lett 32:15. https://doi.org/10.1029/2005GL022436

Tyson PD, Preston-Whyte RA (2000) The weather and climate of Southern Africa. Oxford University Press, Cape Town

Vigaud N, Richard Y, Rouault M, Fauchereau N (2009) Moisture transport between the South Atlantic Ocean and Southern Africa: relationships with summer rainfall and associated dynamics. Clim Dyn 32(1):113-123. https://doi.org/10.1007/s00382-008-0377-7

Walker ND (1990) Links between South African summer rainfall and temperature variability of the Agulhas and Benguela Current systems. J Geophys Res Oceans 95(C3):3297-3319. https://doi.org/ 10.1029/JC095iC03p03297

Xie P, Chen M, Yang S, Yatagai A, Hayasaka T, Fukushima Y, Liu C (2007) A gauge-based analysis of daily precipitation over East Asia. J Hydrometeor 8(3):607-626. https://doi.org/10.1175/ JHM583.1

Xu D, Tian YA (2015) Comprehensive survey of clustering algorithms. Ann Data Sci 2(2):165-193. https://doi.org/10.1007/ s40745-015-0040-1

Wang G, Cai W (2013) Climate-change impact on the 20th-century relationship between the Southern Annular Mode and global mean temperature. Sci Rep 3:2039. https://doi.org/10.1038/srep02039

Wolski P, Jack C, Tadross M, Aardenne L, Lennard C (2018) Interannual rainfall variability and SOM-based circulation classification. Clim Dyn 50(1):479-492. https://doi.org/10.1007/ s00382-017-3621-1

Publisher's note Springer Nature remains neutral with regard to jurisdictional claims in published maps and institutional affiliations. 